Supplement of Earth Syst. Dynam., 10, 205-217, 2019

https://doi.org/10.5194/esd-10-205-2019-supplement

(C) Author(s) 2019. This work is distributed under

the Creative Commons Attribution 4.0 License.

(c) (1)
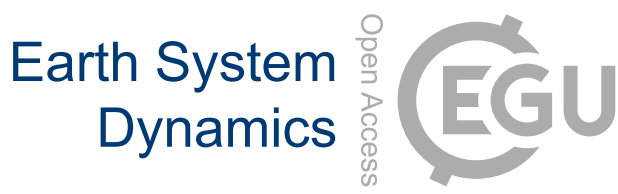

Supplement of

\title{
Freshwater resources under success and failure of the Paris climate agreement
}

Jens Heinke et al.

Correspondence to: Jens Heinke (heinke@pik-potsdam.de)

The copyright of individual parts of the supplement might differ from the CC BY 4.0 License. 
2010
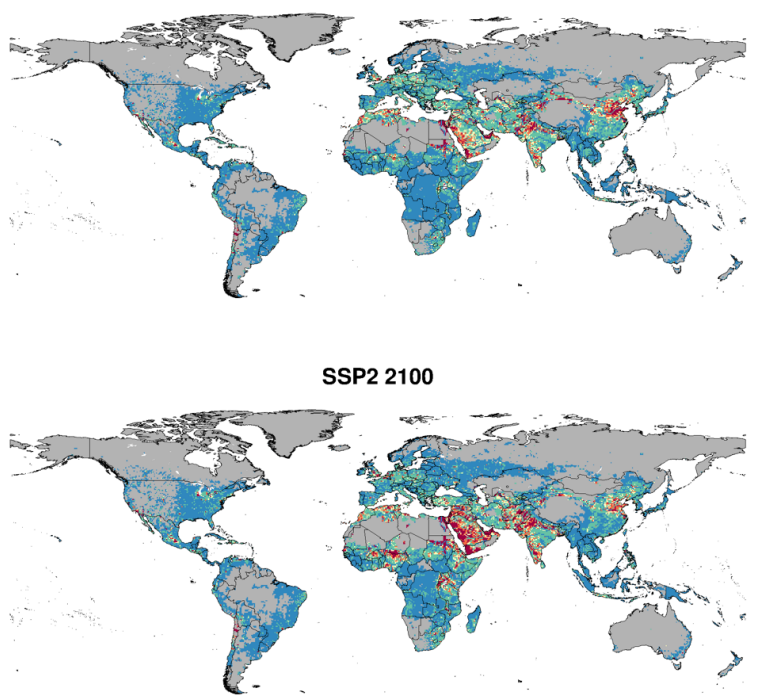

SSP4 2100

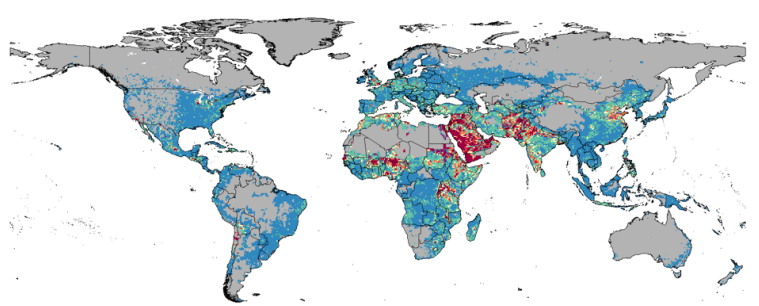

SSP1 2100

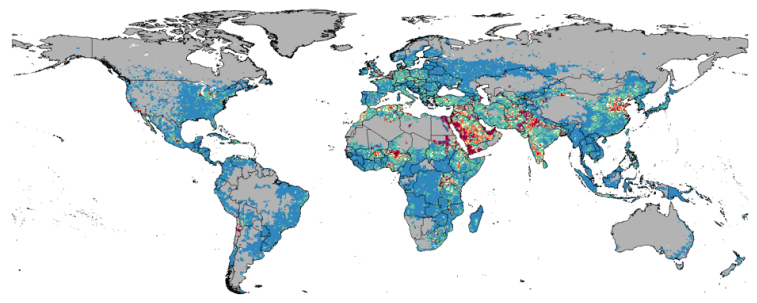

SSP3 2100

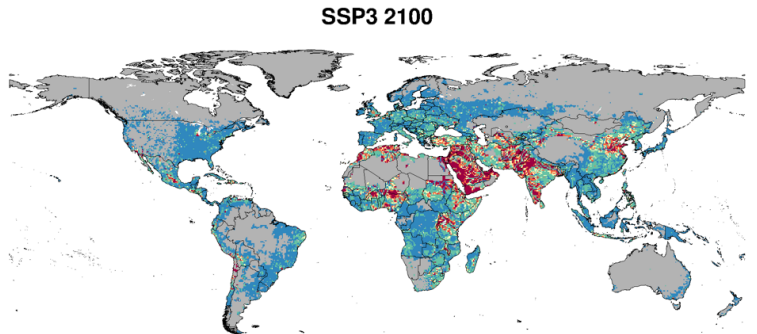

SSP5 2100

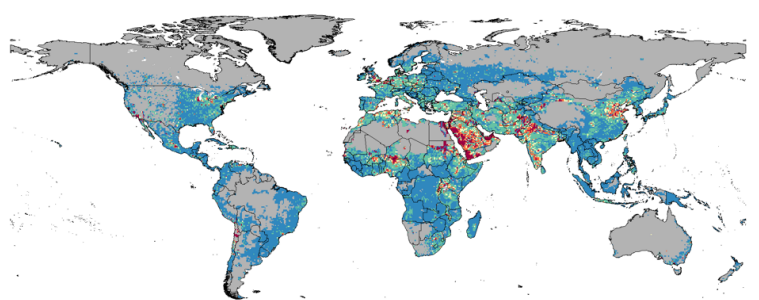

Figure S1: Spatial patterns of water crowding in 2010 and for five different population scenarios in 2100 under current water availability, i.e. assuming no climate change. 

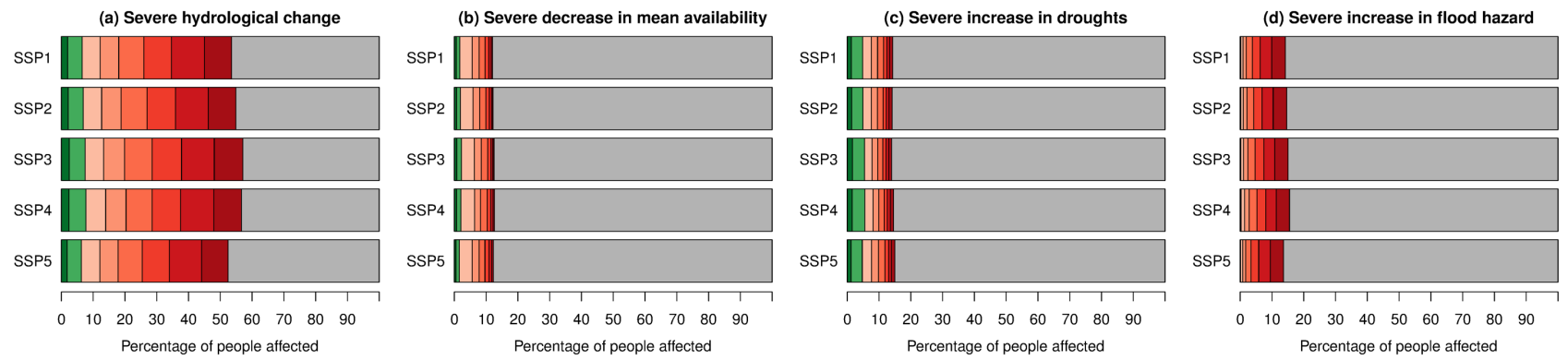

Figure S2: Proportion of total population more likely than not exposed to severe hydrological change at different levels of $\Delta T_{g l o b}$. 


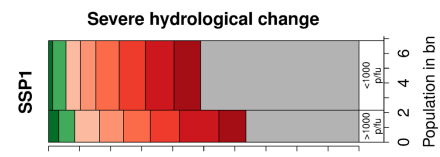

$\begin{array}{llllllllll}0 & 10 & 20 & 30 & 40 & 50 & 60 & 70 & 80 & 90\end{array}$

Percentage of people affected

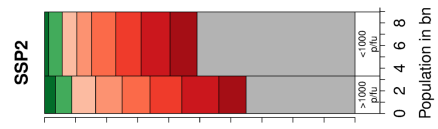

$\begin{array}{llllllllll}0 & 10 & 20 & 30 & 40 & 50 & 60 & 70 & 80 & 90\end{array}$

Percentage of people affected

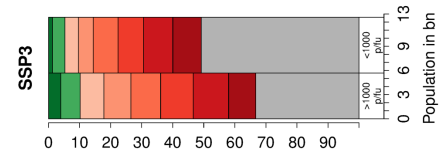

Percentage of people affected

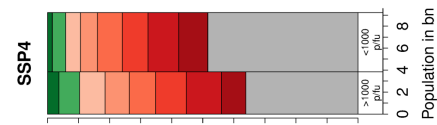

$\begin{array}{llllllllll}0 & 10 & 20 & 30 & 40 & 50 & 60 & 70 & 80 & 90\end{array}$ Percentage of people affected

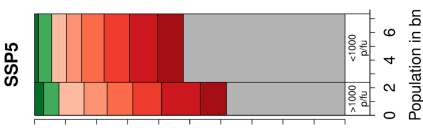

$\begin{array}{llllllllll}0 & 10 & 20 & 30 & 40 & 50 & 60 & 70 & 80 & 90\end{array}$

Percentage of people affected
Severe decrease in mean availability

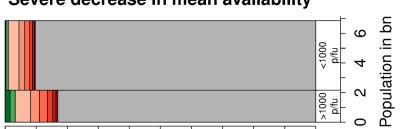

$\begin{array}{llllllllll}0 & 10 & 20 & 30 & 40 & 50 & 60 & 70 & 80 & 90\end{array}$

Percentage of people affected

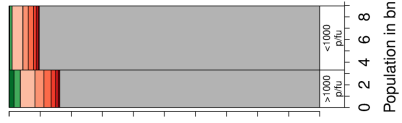

$\begin{array}{llllllllll}0 & 10 & 20 & 30 & 40 & 50 & 60 & 70 & 80 & 90\end{array}$ Percentage of people affected

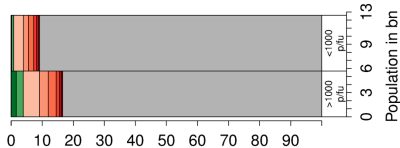

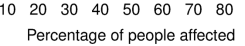

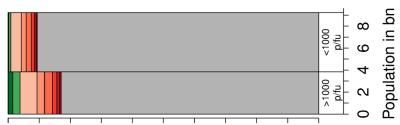

$\begin{array}{llllllllll}0 & 10 & 20 & 30 & 40 & 50 & 60 & 70 & 80 & 90\end{array}$ Percentage of people affected

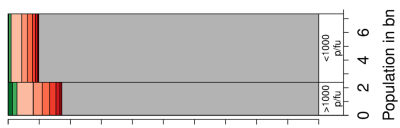

$\begin{array}{lllllllll}10 & 20 & 30 & 40 & 50 & 60 & 70 & 80 & 90\end{array}$

Percentage of people affected
Severe increase in droughts

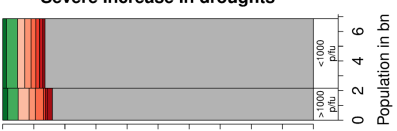

$\begin{array}{lllllllll}10 & 20 & 30 & 40 & 50 & 60 & 70 & 80 & 90\end{array}$

Percentage of people affected

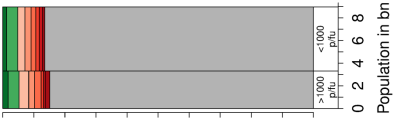

$\begin{array}{llllllllll}0 & 10 & 20 & 30 & 40 & 50 & 60 & 70 & 80 & 90\end{array}$ Percentage of people affected

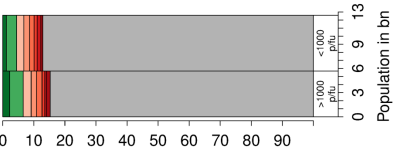
Percentage of people affected

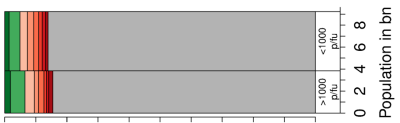

$\begin{array}{llllllllll}0 & 10 & 20 & 30 & 40 & 50 & 60 & 70 & 80 & 90\end{array}$ Percentage of people affected

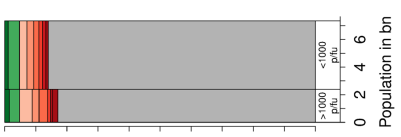

$\begin{array}{lllllllll}10 & 20 & 30 & 40 & 50 & 60 & 70 & 80 & 90\end{array}$
Severe increase in flood hazard

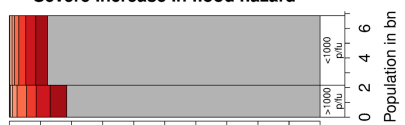

$\begin{array}{llllllllll}0 & 10 & 20 & 30 & 40 & 50 & 60 & 70 & 80 & 90\end{array}$

Percentage of people affected

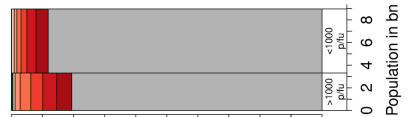

$\begin{array}{llllllllll}0 & 10 & 20 & 30 & 40 & 50 & 60 & 70 & 80 & 90\end{array}$ Percentage of people affected

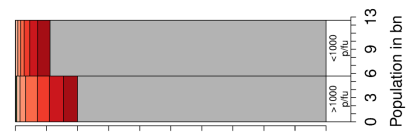

$\begin{array}{llllllllll}0 & 10 & 20 & 30 & 40 & 50 & 60 & 70 & 80 & 90\end{array}$ Percentage of people affected

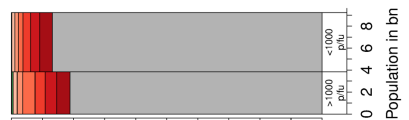

\begin{tabular}{llllllllll}
\hline 0 & 10 & 20 & 30 & 40 & 50 & 60 & 70 & 80 & 90
\end{tabular} Percentage of people affected

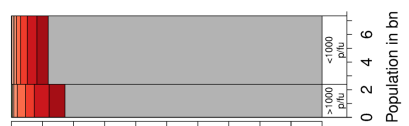

$\begin{array}{llllllllll}0 & 10 & 20 & 30 & 40 & 50 & 60 & 70 & 80 & 90\end{array}$ ercentage of people affected

Figure S3: Fraction of population in 2100 exposed to severe hydrological change at different levels of $\Delta T_{\text {glob }}$ divided over two water scarcity categories: population already experiencing absolute water scarcity $(>1000 \mathrm{p} / \mathrm{fu})$ in the absence of climate change and rest of population $(\leq 1000 \mathrm{p} / \mathrm{fu})$. The total number of people in each class is given on the $y$-axis, and the fraction of people exposed to sever hydrological change in each class is given on the $\mathrm{x}$-axis. 


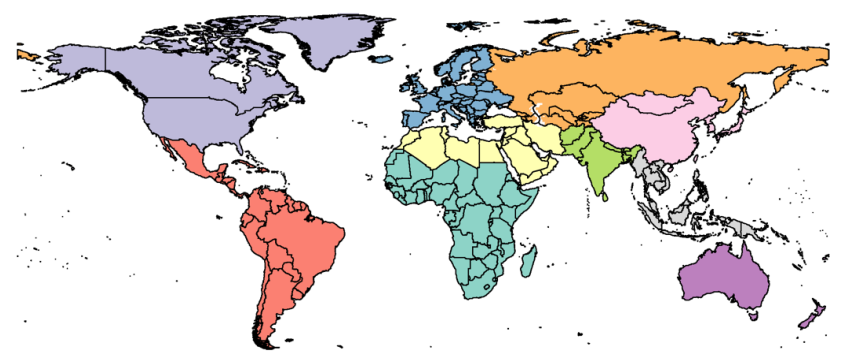

$\square$ Sub-Saharan Africa (SSA)
$\square$ Middle East and North Africa (MEA)
$\square$ North America (NAM)
$\square$ Latin America (LAM)
$\square$ Europe (EUR)
$\square$ Russia and Central Asia (RGA)
$\square$ South Asia (SAS)
$\square$ East Asia (EAS)
$\square$ Southeast Asia (SEA)
$\square$ Australia and New Zealand (ANZ)

Figure S4: Map of world regions. 

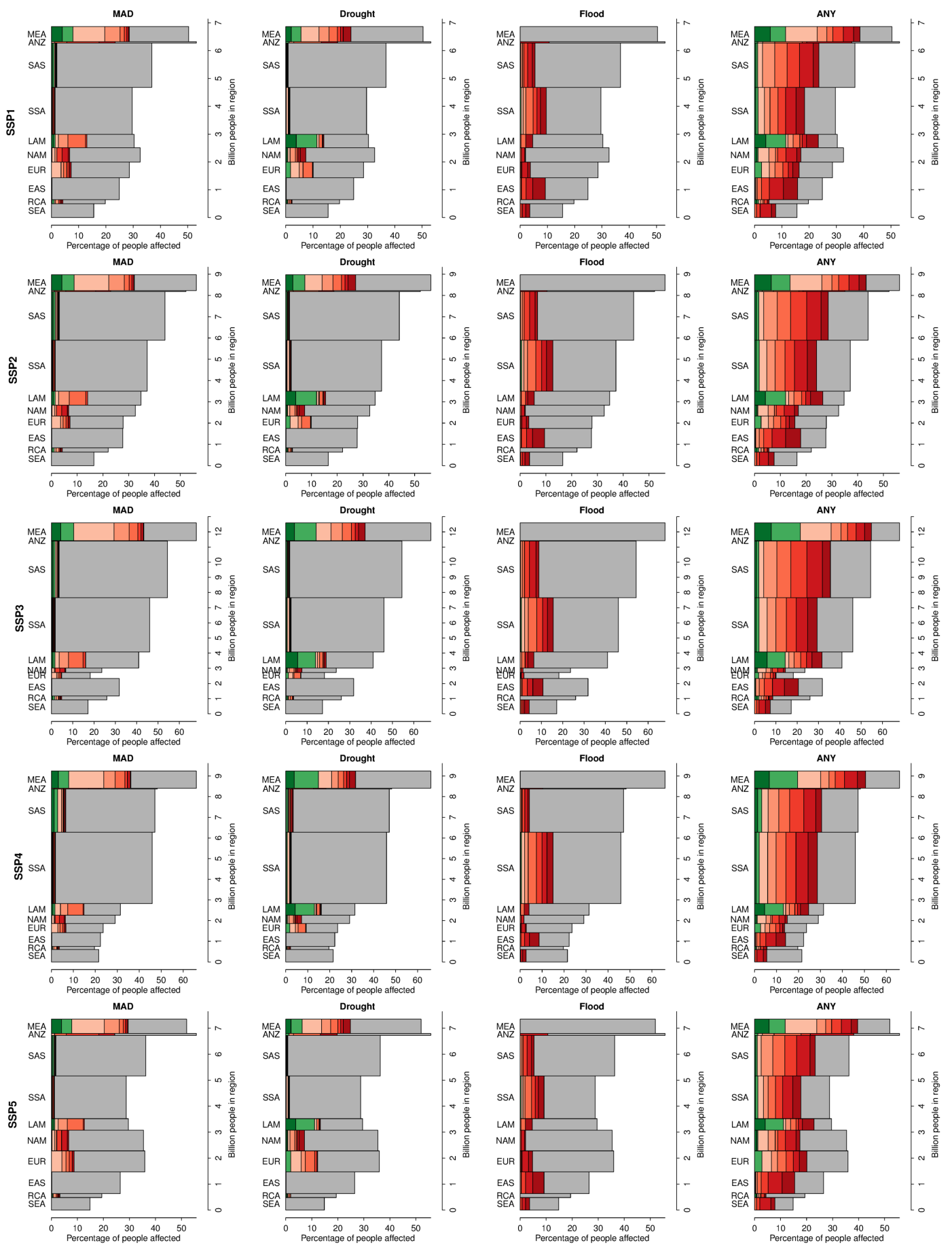

Figure S5: Proportion of population in 2100 in different world regions that would experience absolute water scarcity $(>1000 \mathrm{p} / \mathrm{fu}$ ) under present-day climate conditions (total length of bar) and be more likely than not exposed to severe hydrological change at different levels of $\Delta T_{g l o b}$. 

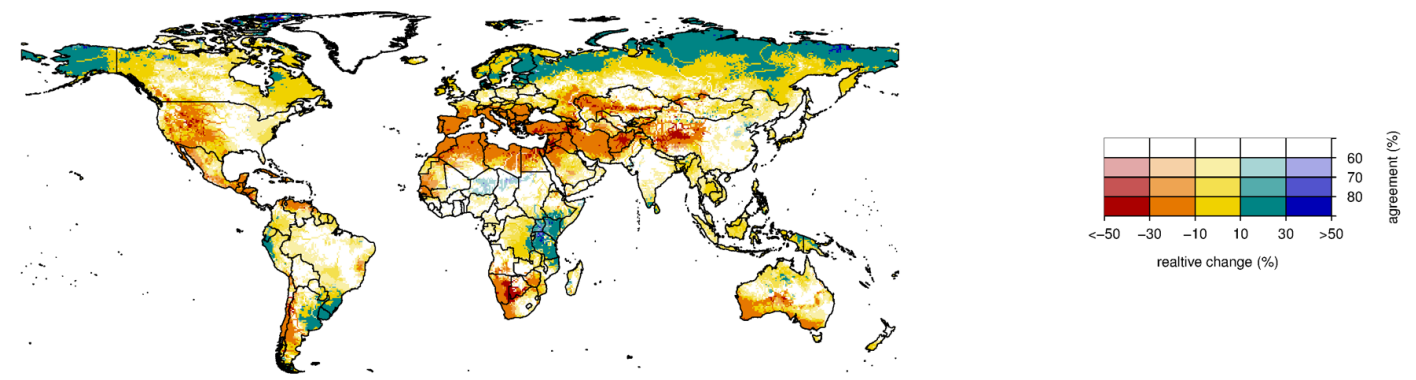

Figure S6: Relative change in MAD compared to control simulation for a $\Delta T_{\text {glob }}$ (above pre-industrial level) of $2.5^{\circ} \mathrm{C}$. Color hues show the multimodel mean change, and saturation shows the agreement on the sign of change across all GCMs (percentage of GCMs agreeing on the sign). Because $\Delta T_{g l o b}$ for the control simulation is $0.6^{\circ} \mathrm{C}$, the changes are representative for $1.9^{\circ} \mathrm{C}$

5 additional warming relative to the control simulation and can thus be compared to the changes for $2^{\circ} \mathrm{C}$ additional warming shown in Fig. 1 in Schewe et al. (2014). 